\section{Maternal methyldopa treatment and neonatal blood pressure}

Methyldopa is widely used to treat hypertension in pregnancy. Redman et $a^{1}$ reported a controlled trial in which fetal loss in hypertensive patients was reduced in a group given methyldopa compared with an untreated group. Methyldopa is readily transferred across the placenta, and Jones $e t$ al $^{2}$ found cord blood concentrations to be as high as maternal plasma concentrations. The drug is eliminated by sulphation and excretion and is detectable in neonatal plasma up to four days after birth. ${ }^{2}$ It produces modest reductions in blood pressure (5-6 $\mathrm{mm} \mathrm{Hg}$ ) in normotensive people, though much greater reductions occur in hypertensive adults with high plasma renin concentrations. ${ }^{3}$ Interference with a newborn infant's vasomotor control might have serious consequences if the infant was also affected by hypoxia, hypovolaemia, or cardiac disease, as perfusion of vital organs might be impaired. This study was aimed at determining whether systolic blood pressure was lower in infants of mothers treated with methyldopa than in infants of the same birth weight whose mothers had not received hypotensive drugs.

\section{Patients, methods, and results}

Over about 12 months 24 mothers given methyldopa were delivered after 37 or more weeks of gestation. The indications for treatment were either long-standing hypertension before pregnancy treated with an antihypertensive drug or a diastolic blood pressure consistently higher than $95 \mathrm{~mm} \mathrm{Hg}$ before 28 weeks of pregnancy. The dose of methyldopa ranged from 500 $\mathrm{mg}$ to $2 \mathrm{~g}$ a day. Systolic blood pressure was measured in the newborn infants at $12,36,60,84$, and 108 hours after delivery using a $5 \mathrm{~cm}$ wide Pedisphyg cuff, Parks Doppler blood-flow detector, and mercury sphygmomanometer. The Pedisphyg and Parks Doppler system have been validated against direct intra-arterial pressure measurements in infants $(r=0.99){ }^{4}$ The cuff was applied to the right arm and the systolic blood pressure measured when the baby was awake, quiet, and not being fed. Duplicate measurements were made by one or two specially trained nursing sisters. Mean interobserver difference was $3.1 \mathrm{~mm} \mathrm{Hg}$, but there was no consistent bias.

The 24 full-term infants of the mothers treated with methyldopa were compared with a group of 50 randomly selected full-term infants whose mothers had not received antihypertensive drugs. Resting systolic blood pressure was measured in the control infants in the same way as in the infants of mothers treated with methyldopa. The table shows that birth weight and gestational age were not significantly different between the two groups.

The systolic blood pressure in the full-term infants of mothers given methyldopa was 4.5 and $4.3 \mathrm{~mm} \mathrm{Hg}$ lower than the control blood pressure during days 1 and 2 respectively. By days 3,4 , and 5 there was no significant difference between the two groups. None of the infants of mothers treated with methyldopa showed a heart rate of below 120/minute. Three of these infants were tilted from horizontal to vertical while blood pressure and heart rate were measured; no change in either variable was found.

There were three cases of fetal distress in labour at term (type II fetal heart decelerations), but all of these babies had one-minute Apgar scores of six or more and were in good condition. Three of the 24 babies had one-minute Apgar scores below six, but all had an Apgar score of seven or more by five minutes.

\section{Comment}

These results show that the full-term infants of mothers treated with methyldopa had a significantly reduced systolic blood pressure during the first two days after delivery. The decrease in blood pressure (4-5 $\mathrm{mm} \mathrm{Hg}$ ) was comparable with that found when methyldopa is administered to normotensive adults. ${ }^{3}$ The duration of decreased blood pressure was consistent with the slow elimination of the drug by the neonate, normal blood pressures being achieved by about three days, when plasma methyldopa concentrations are low. The mild reduction in blood pressure should not seriously compromise the babies, and there was no evidence that their cardiovascular systems were unable to respond to stress.
I thank the two nursing sisters, Cathy Lawrence and Mary Courtnell, who carried out many of the blood pressure measurements.

${ }^{1}$ Redman CWG, Beilin LJ, Bonnar J, Ounsted MK. Fetal outcome in trial of antihypertensive treatment in pregnancy. Lancet 1976;ii:753-6.

2 Jones HMR, Cummings AJ, Setchell KDR, Lawson AM. A study of the disposition of $\alpha$-methyldopa in newborn infants following its administration to the mothers for the treatment of hypertension during pregnancy Br f Clin Pharmacol 1979;7:433-40.

${ }^{3}$ Weidmann P, Hirsch D, Maxwell MH, Okun R. Plasma renin and blood pressure during treatment with methyldopa. Am f Cardiol 1974;34:671-6.

${ }^{4}$ Reder RF, Dimich I, Cohen M, Steinfeld L. Evaluating indirect blood pressure measurement techniques in a comparison of three systems in infants and children. Pediatrics $1978 ; 62: 326-30$.

(Accepted 29 May 1981)

Division of Perinatal Medicine, Clinical Research Centre and Northwick Park Hospital, Harrow, Middlesex HA1 3UJ

ANDREW WHITELAW, MD, MRCP, consultant paediatrician (present address: department of paediatrics and neonatal medicine, Hammersmith Hospital, London W12 0HS)

\section{Narcotic withdrawal syndrome after intrathecal administration of morphine}

Intrathecal morphine is now widely used ${ }^{12}$ as an acceptable alternative to systemically administered postoperative narcotic analgesics. Tung $e t a l^{3}$ reported a case of opiate withdrawal after intrathecal morphine was given to relieve chronic cancer pain. We report the occurrence of this syndrome in a patient given intrathecal morphine to relieve postoperative pain.

\section{Case report}

An otherwise fit 43-year-old woman was admitted with ischaemic pain in both legs. While awaiting investigations at another hospital she had developed severe pain at rest in the right leg, causing her to stop working.

Bilateral femoral arteriograms showed complete block of both femoral arteries. She was receiving naftidrofuryl oxalate and dextran 40 .

Before admission she had been taking dihydrocodeine tartrate two tablets four to six hourly. Three weeks before admission she had started taking dipipanone, which had been gradually increased to $20 \mathrm{mg}$ four hourly. Four days before operation the pain intensified. She was given papaveretum 10 mg four hourly for two days, then pethidine $50 \mathrm{mg}$ two hourly, then morphine $15 \mathrm{mg}$ three hourly, which resulted in only partial pain relief. About 36 hours after starting morphine she underwent right profundoplasty and lumbar sympathectomy. At operation she was given additive-free, preservative-free morphine $2 \mathrm{mg}$ intrathecally at the L2-3 interspace. This gave complete postoperative pain relief.

Having been well for two days, on the third postoperative day she became confused and disorientated. The next day she was restless and drowsy and looked pale and tired. She experienced visual and auditory hallucinations. She became anorexic and incontinent and had insomnia. She made several confused preparations to discharge herself from the hospital. By the end of the fifth postoperative day she was apparently normal. There was no further distress or hallucinations. Her appetite returned and she left hospital on the twelfth postoperative day.

\section{Comment}

Physical dependence on a drug is an altered physiological state produced by the repeated administration of that drug to prevent the appearance of a stereotypical syndrome. The time required to produce

Mean $+S D$ systolic blood pressure $(\mathrm{mm} \mathrm{Hg})$ in infants of mothers given methyldopa and control infants born at term

\begin{tabular}{|c|c|c|c|c|c|c|c|c|}
\hline & \multirow[b]{2}{*}{ No } & \multirow{2}{*}{$\begin{array}{l}\text { Birth weight } \\
(\mathrm{g})\end{array}$} & \multirow{2}{*}{$\begin{array}{c}\text { Gestation } \\
\text { (weeks) }\end{array}$} & \multicolumn{5}{|c|}{ Blood pressure } \\
\hline & & & & 12 hours & 36 hours & 60 hours & 84 hours & 108 hours \\
\hline $\begin{array}{l}\text { Control infants } \\
\text { Methyldopa infants }\end{array}$ & $\begin{array}{l}50 \\
24\end{array}$ & $\begin{array}{l}3227 \div 462 \\
3212 \div 415\end{array}$ & $\begin{array}{l}39 \cdot 2 \pm 1 \cdot 1 \\
38 \cdot 8+0 \cdot 7\end{array}$ & $\begin{array}{l}63 \cdot 5 \pm 6 \cdot 5 \\
59 \cdot 0 \pm 7 \cdot 0^{*}\end{array}$ & $\begin{array}{l}68 \cdot 0 \pm 8 \cdot 0 \\
63 \cdot 7 \pm 8 \cdot 9 \dagger\end{array}$ & $\begin{array}{l}71 \cdot 0+9 \cdot 0 \\
68 \cdot 9 \cdot 9 \cdot 3\end{array}$ & $\begin{array}{l}76 \cdot 0 \pm 10 \cdot 0 \\
74 \cdot 4 \pm 8 \cdot 6\end{array}$ & $\begin{array}{l}77 \cdot 0 \pm 10 \cdot 0 \\
79 \cdot 6 \pm 11 \cdot 6\end{array}$ \\
\hline
\end{tabular}

Significance of difference from control infants: ${ }^{*} \mathrm{p}<0.01 ;+\mathrm{p}<0.05$ (Student's $t$ test). 
physical dependence varies, the most important factor being the degree to which function of the central nervous system is altered by the drug. ${ }^{4}$

Our patient received a substantial quantity of powerful drugs acting on the central nervous system over a fairly short period to combat severe pain. In the postoperative period there was no pain and all systemic analgesics were therefore stopped. She then developed the withdrawal syndrome.

Normally after a major operation patients require opiate analgesics to relieve pain. Opiate withdrawal symptoms, consequent on preoperative iatrogenic preconditioning, are therefore highly unlikely in the early postoperative stage. Gradually as postoperative pain stops the analgesics are reduced, and this permits some weaning from the narcotic. In this case the morphine acted more effectively in one part of the body (the spinal cord) after the operation than it had done before the operation and yet less effectively in another part, causing withdrawal symptoms. It was this that was so disconcerting and unexpected. Indeed, the diagnosis was made only retrospectively after her complete recovery, coinciding with negative results of all laboratory investigations.

As the use of intrathecal morphine increases more patients may develop withdrawal symptoms in the postoperative period, and doctors should therefore be warned of this possibility. Since opiate withdrawal symptoms are easily relieved it is to the patient's immediate benefit that the diagnosis is made early and appropriate treatment begun.

${ }^{1}$ Mathews ET, Abrams LD. Intrathecal morphine in open heart surgery. Lancet 1980 ;i : 543 .

${ }^{2}$ Gjessing J, Tomlin PJ. Postoperative pain control with intrathecal morphine. Anaesthesia $1981 ; 36: 268-76$

${ }^{3}$ Tung AS, Tenicela R, Winter PM. Opiate withdrawal syndrome following intrathecal administration of morphine. Anesthesiology 1980;53 340.

${ }^{4}$ Jerome $\mathrm{H}$ Jaffe. Drug addiction and drug abuse. In: Goodman LS, Gilman A, eds. The pharmacological basis of Therapeutics. 6th ed. New York: Macmillan Publishing Co Inc, 1980 : 535-84.

(Accepted 19 May 1981)

University Department of Anaesthetics, Queen Elizabeth Hospital Birmingham B15 2TH

F M MESSAHEL, FFARCS, senior registrar

P J TOMLIN, FFARCS, senior lecturer

\section{False-negative results of Hemoccult test in colorectal cancer}

Testing for faecal occult blood using the Hemoccult test (Smith Kline Instrument $\mathrm{Co}$ ) has been advocated for screening for colorectal cancer in populations at risk, ${ }^{1}$ and its use is suggested for detecting early recurrence after resection of cancers of the colon and rectum. False-negative reactions occur with the Hemoccult test ${ }^{2}$ in patients with proved carcinoma of the large bowel and rectum.

In our series of patients the false-negative results of tests for occult blood corresponded to the lack of surface ulceration of the tumour.

\section{Patients, methods, and results}

Twenty-eight patients with histologically proved carcinoma of the colon and rectum were studied prospectively. Before bowel preparation for operation was started three consecutive stools from each patient were each tested in two separate places using the Hemoccult cards as recommended by Greegor $^{1}$ (in four patients only two consecutive stool specimens were obtained for testing). The patients were not placed on a meat-free diet since this restriction is unnecessary according to the manufacturer's instruction leaflet. No patient received vitamin C supplements, a recognised cause of false-negative reactions. ${ }^{2}$ As each test was read at 30 seconds, there were no false-negative results related to the storage of specimens. ${ }^{3}$ Weak positive reactions were classified as positive for faecal occult blood.
Results of Hemoccult test for faecal occult blood in 28 patients with histologically proved carcinoma of the colon and rectum

\begin{tabular}{cccc}
\hline $\begin{array}{c}\text { No of positive results } \\
\text { (out of 6) }\end{array}$ & No of patients & $\begin{array}{c}\text { No of patients with } \\
\text { ulcerated tumour }\end{array}$ & $\begin{array}{c}\text { No of patients with } \\
\text { non-ulcerated tumour }\end{array}$ \\
\hline 0 & 5 & 0 & 5 \\
1 & 1 & 0 & 1 \\
2 & 4 & 4 & 0 \\
4 & 7 & 5 & 2 \\
6 & 11 & 11 & 0
\end{tabular}

Each patient underwent resection of the tumour, and the presence or absence of ulceration of the tumour was recorded after examination of the resected specimen.

Occult blood was found in the stools of 23 patients, of whom 21 had ulcerated tumours (see table). Five patients failed to yield any positive results on tests for faecal occult blood despite having a proved carcinoma all of these patients had non-ulcerated Dukes B tumours-that is, local spread through the bowel wall but no regional lymph node metastases.

\section{Comment}

Carcinomas of the large bowel and rectum are known to shed blood, which can be detected in the faeces. The initial experience with the guaiac resin test for faecal occult blood led to a reduction in sensitivity because of the high numbers of false-positive reactions. ${ }^{1}$ The manufacturers claim, however, that the Hemoccult test has detected blood in vitro in a dilution of $1 / 5000$; this should detect a blood loss of $0.04 \mathrm{ml} / 24$ hours in the average stool of $75-200 \mathrm{~g}$ (UK figures). Heinrich, ${ }^{4}$ however, reported false-negative reactions with the Hemoccult with measured faecal blood losses of $25 \mathrm{ml} / 24$ hours for reasons not yet fully understood. An increasing number of falsenegative reactions using the Hemoccult tests with decreasing size of tumour as measured by the mean area was reported by Songster et al,,$^{5}$ but they made no comment about the surface characteristics of the lesion.

Our study indicates that ulceration of the tumour is an important factor in the false-negative hemoccult reaction. It is logical to presume that non-ulcerated tumours are less likely to bleed into the lumen of the bowel, and hence a negative result of a test for faecal occult blood would result despite the presence of a carcinoma.

Serial Hemoccult testing is widely used as a screening test for colorectal cancer. The results of our preliminary study suggest that an appreciable number of non-ulcerated tumours would be missed.

${ }^{1}$ Greegor DH. Diagnosis of large bowel cancer in the asymptomatic patient. F AMA 1967;201:943-5.

2 Jaffee RM, Kaston B, Young MD, MacLowry N. False negative stool occult blood tests caused by ingestion of ascorbic acid (vitamin C) Ann Intern Med 1974;83:824-6.

${ }^{3}$ Fleisher M, Schwartz MK, Winawer SJ. The false negative haemoccult test. Gastroenterology 1977;72:782-4.

${ }^{4}$ Heinrich HC. Occult blood tests. Lancet 1980; : $822-3$.

5 Songster CL, Barrows GH, Jarrett DD. Immunochemical detection of faecal occult blood. Cancer $1980 ; 45: 1099-102$.

(Accepted 20 May 1981)

Western General Hospital, Edinburgh EH4 2XU

C D M GRIFFITH, FRCSED, surgical registrar, gastrointestinal unit D J TURNER, $\mathrm{MB}$, $\mathrm{CHB}$, surgical senior house officer, general surgical unit J H SAUNDERS, FRCSGLAS, consultant surgeon, gastrointestinal unit

\section{Correction}

Anaphylactic reaction to low-molecular-weight porcine factor VIII concentrates

An error occurred in this paper by Drs J G Erskine and J F Davidson (20 June, $\mathrm{p} 2011$ ). In lines 8 and 9 of the case report "an intramuscular injection of $10 \mathrm{mg}$ chlorpheniramine maleate" should have read: "an intravenous injection ..." 